\title{
Clean technologies and policies for sustainable development in Asia
}

\author{
Chew Tin Lee ${ }^{1} \cdot$ Petar Sabev Varbanov ${ }^{2} \cdot$ Chunjie Li $^{3} \cdot$ Yee Van Fan ${ }^{2}$
}

Published online: 19 November 2019

(c) Springer-Verlag GmbH Germany, part of Springer Nature 2019

The population in Asia is estimated to rise to $5.3 \times 10^{9}$ by 2050 according to the United Nations, and the economy is expected to triple in size by 2040 . Asian countries will be the key players in contributing to environmental footprints mitigation, which includes the GHG emissions. This role presents both opportunities and challenges in decoupling the emissions from the nations' rate of development. Assessment, optimisation and process design to drive the low GHG emissions development—e.g. renewable energy, waste as resources, cleaner production, policy and regulation, are receiving high research attention recently. Measures towards sustainability require continuous consensus building and involvement of various stakeholders at local and international levels. International conferences serve as one the platforms to address these issues.

Close to 200 international and local experts from various countries-including the state officials from various ministries, state departments and local authorities and academia, attended the 3rd International Conference on Low Carbon Asia 2017 (ICLCA'17) during 1-3 November 2017, with the theme "Sustainable Low Carbon Emission Development in Asia". ICLCA'17 was held jointly with the 6th LoCARNet Annual Meeting in Century Park Hotel, Bangkok, Thailand. ICLCA serves as a high-impact platform, bringing together researchers and multi-stakeholders from academia, government and private sectors, to share the knowledge and experiences for the transformation towards low-carbon development in Asia and beyond, for the emerging technologies and

Chew Tin Lee

ctlee@utm.my

1 School of Chemical and Energy Engineering, Universiti Teknologi Malaysia (UTM), 81310 Johor Bahru, Johor, Malaysia

2 Sustainable Process Integration Laboratory - SPIL, NETME Centre, Faculty of Mechanical Engineering, Brno University of Technology, - VUT Brno, Technická 2896/2, 61600 Brno, Czech Republic

3 School of Environmental Science and Engineering, Shanghai Jiao Tong University, Shanghai 200240, China scientific advancements in a wide range of sustainability topics. The LoCARNet is a network for multilayered stakeholders to promote research cooperation related to low-carbon growth and policy making. The key members of LoCARNet are from the ASEAN + 3 countries (Japan, China and Republic of Korea) as led by the Secretariat based in the Institute for Global Environmental Strategies (IGES), Japan. Two series of the LoCARNet Annual Meetings have joined the ICLCA in 2015 and 2017. The joint conference addressed the various challenges outlined under the United Nations' Sustainable Development Goals (SDGs).

The joint event featured five (5) keynote speeches, nine (9) breakout sessions with 120 presenters from 15 countries. The activities cover key topics and issues related to the current situation, challenges, and future policy directions of climate change mitigation and adaptation in Asia. Six major thematic topics were included in this joint conference, indicating its multidisciplinary and holistic approach for sustainable solutions.

The topics included:

1. Building and design

2. Urban development

3. Land use and agriculture

4. Energy system and scenario

5. Policies and mechanisms

6. Behaviour Change and Consumption

A Scientific Committee consisting of 30 world-leading personalities reviewed the 150 papers submitted for the oral and poster presentation for the joint conference. Following further selection procedures, 30 invitations have been sent to the authors to submit manuscripts to Clean Technologies and Environmental Policy.

Eight articles have been finally accepted to a special section of this issue of Clean Technologies and Environmental Policy, entitled "Clean Technologies and Policies for Sustainable Development in Asia". The focus of the articles is on greenhouse gas footprints assessment and minimisation, 
ecological footprints, reuse of waste, practical case studies, the use of thermodynamics in sustainability assessment.

The Guest Editors would like to thank the International Scientific Committee Members especially those engaged in reviewing the papers. The CTEP journal publisher, Editor in Chief and Production Editor deserve the thanks of supporting this publication.

Publisher's Note Springer Nature remains neutral with regard to jurisdictional claims in published maps and institutional affiliations. 